Pract. oto-rhino-laryng. 1967;29:281-283

\title{
H.A.E. Van Dishoeck on the occasion of his retirement
}

From 1951-1967 Prof. Dr. H. A. E. van Dishoeck has been Professor of Otorhinolaryngology at the University of Leiden.

During these sixteen years a great number of international and national activities have taken place in our field of science as a direct result of his many initiatives.

About 40 otorhinolaryngologists have received their professional training and a part of their scientific education under his guidance, in this period.

Now, on the occasion of his retirement, his pupils wish to express their gratitude by dedicating to him this issue of scientific contributions.

E. H. Huizing jr. (editor) L. A. J. van L·ier P. H. Schmidt 